\title{
Bruno Laurioux, Écrits et images de la gastronomie médiévale
}

\section{Maria Colombo Timelli}

\section{(2) OpenEdition}

\section{Journals}

Édition électronique

URL : http://journals.openedition.org/studifrancesi/3335

DOI : 10.4000/studifrancesi.3335

ISSN : 2421-5856

Éditeur

Rosenberg \& Sellier

Édition imprimée

Date de publication : 1 avril 2013

Pagination : 150

ISSN : 0039-2944

Référence électronique

Maria Colombo Timelli, « Bruno Laurioux, Écrits et images de la gastronomie médiévale », Studi Francesi [En ligne], 169 (LVII | I) | 2013, mis en ligne le 30 novembre 2015, consulté le 18 septembre 2020. URL : http://journals.openedition.org/studifrancesi/3335; DOI : https://doi.org/10.4000/studifrancesi.3335

Ce document a été généré automatiquement le 18 septembre 2020.

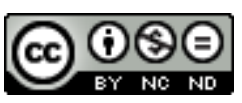

Studi Francesi è distribuita con Licenza Creative Commons Attribuzione - Non commerciale - Non opere derivate 4.0 Internazionale. 


\title{
Bruno Laurioux, Écrits et images de la gastronomie médiévale
}

\author{
Maria Colombo Timelli
}

\section{RÉFÉRENCE}

BRUNO LAURIOUX, Écrits et images de la gastronomie médiévale, Paris, Bibliothèque nationale de France (Conférences Léopold Delisle), 2011, pp. 95.

1 Ce recueil précieusement illustré réunit les textes de quatre conférences données à la BnF en novembre-décembre 2004: si ces chapitres n'ont pas l'apparence d'articles scientifiques, n'étant pas accompagnés d'un gros apparat de notes en bas de page, ils s'avèrent riches en informations et précieux dans la mesure où leur auteur y fait le point de main de maître sur un certain nombre de questions qui intéressent les spécialistes de plusieurs disciplines: histoire, histoire du livre, histoire littéraire. À la base de ces réflexions, un constat: loin d'avoir attendu la Révolution française, un «discours gastronomique» s'est mis en place au Moyen Âge déjà, et s'est perfectionné dans les deux derniers siècles de cette époque, qui ont surtout retenu l'attention de l'Auteur.

2 Le premier «article» (L'apparition des livres de cuisine et la codification des pratiques culinaires, pp. 25-42) dresse une typologie des livres de cuisine produits aux XIV et $\mathrm{XV}^{\mathrm{e}}$ siècles, en prenant en compte forme matérielle (du rouleau au codex universitaire au livre imprimé du XVI ${ }^{\mathrm{e}}$ siècle) et contenu / organisation des livres de recettes. On passe ensuite (Entre l'Église et la Faculté: la difficile affirmation de la 'gula', pp. 43-58) à l'analyse de deux visions de la gula: celle de l'Église, aux yeux de laquelle ce vice demeure un péché capital, surtout dans ses excès, et celle de la médecine, mettant en rapport qualités des aliments et leurs effets sur les différents tempéraments des hommes. Si ces deux visions évoluent au cours des siècles, elles ont en commun d'aborder la question $\mathrm{du}$ rapport, moral et physique, entre alimentation et plaisir. Avec la troisième conférence, c'est la «veine littéraire de la gastronomie» qui est envisagée (Le goût des 
mets et les mots du goût dans la littérature française de la fin du Moyen Âge, pp. 59-70); parmi les textes rappelés ou analysés, signalons la Vie de saint Hareng, très tôt imprimée, le Roman du comte d'Anjou (qui contient une longue liste de mets), les poèmes d'Eustache Deschamps et, pour le théâtre, la Condamnation de Banquet de Nicolas de la Chesnaye (début du $\mathrm{XVI}^{\mathrm{e}}$ siècle). Les compétences de B.L. lui permettent de conclure que la «cuisine littéraire» est loin d'être "purement imaginaire» (p. 68). Le dernier sujet retenu est le spectacle par excellence de la fin du Moyen Âge, à savoir le banquet dans la Bourgogne des ducs Valois, où les mets cèdent le pas - tout au moins dans les descriptions qui nous en sont parvenues - au côté spectaculaire, et en particulier à ces «entremets» qui ne cessent de nous interpeller dans la mesure où leur interprétation n'est pas toujours univoque. B.L. n'oublie d'ailleurs pas de rappeler d'autres aspects marquants de la civilisation du repas de cette époque: étiquette, service de table, manuels de "civilité» (La normalisation des arts de la table: l'apogée du banquet au XVe siècle, pp. 71-83).

La bibliographie (pp. 85-94) est raisonnée: elle recoupe les sujets des quatre conférences, et contient des commentaires utiles. Signalons aussi le dossier iconographique: dix-sept images en couleur (pp. 7-24) pour la plupart des manuscrits des collections de la BnF, d'autres en noir et blanc (reproduction d'incunables et imprimés anciens, et d'autres documents), qui complètent très utilement les propos de B.L. 